\title{
UM BREVE OLHAR SOBRE A AUTONOMIA DE JOVENS UNIVERSITÁRIOS EM CAMPO GRANDE NO PERÍODO DE 2012 A $2017^{1}$
}

\section{Un Breve Mirar Sobre La Autonomia De Jóvenes Universitários Em Campo Grande En El} Período De 2012 A 2017

\author{
Priscila Palhanos ${ }^{2}$ \\ Heitor Romero Marques ${ }^{3}$
}

RESUMO: O presente artigo relata como se organizam estudantes universitários que não vivem com os pais em Campo Grande, no período de 2012 a 2017, no sentido de saber como esses jovens se relacionam, quais estruturas desenvolveram - ou não- de autonomia para que possam iniciar a fase adulta em termos sociopsicológicos. Foi também estudados os conceitos, as vantagens e desvantagens da liberdade e medos desses jovens. Por meio de um questionário aplicado com ênfase na metodologia qualitativa e quantitativa a 23 jovens que se deslocaram a Campo Grande no período indicado, a fim de cursar uma universidade e ter novas experiências, longe de seus pais. Foram também consultados artigos e matérias em sites. A pesquisa enquadra-se na tendência empírico-analítico. Os jovens apresentaram forte dificuldade em administrar, principalmente, questões financeiras, pois isso não era uma prática corriqueira para eles nas casas dos pais. Embora em outras áreas já exista uma determinada facilidade - como na limpeza da casa-, a inexperiência em coordenar as atividades de estudos, trabalho, burocracias e vida social ainda pesa na vida desses jovens.

Palavras Chave: Dificuldades. Acadêmicos, Superação

RESUMEN: El presente artículo relata como se organizam estudiantes universitários que no viven con los padres em Campo Grande, en el período de 2012 a 2017, com el sentido de saber como ellos se relacionan, que estructura desarrollaram - o no - de autonomia para que puedan empenzar la fase adulta em términos soiosicológicos. Fueran también estudiados los conceptos, las ventajas y desventajas de la libertad y miedos de eses jóvenes. Por intermedio de un cuestionario aplicado con enfase en la metodologia cuantitativa y cualitativa a 23 jóvenes que vinieran a Campo Grande en el

\footnotetext{
${ }^{1}$ Trabalho apresentado à Universidade Católica Dom Bosco - Programa de Pós Graduação: mestrado acadêmico e Doutorado em Desenvolvimento Local em Contexto de Territorialidades, como resultado de pesquisa no Grupo de Trabalho Economia criativa, aprendizagem e a solidariedade ativa na dinâmica territorial, Planejamento Urbano e Regional.

${ }^{2}$ Licenciada em História e Teologia. Mestranda do Programa de Pós Graduação: mestrado acadêmico e Doutorado em Desenvolvimento Local em Contexto de Territorialidades. Contato: pri.palhanos@gmail.com

${ }^{3}$ Licenciado em Ciências e Pedagogia, Especialista em Filosofia e História da Educação, Mestre em Educação formação de professores, Doutor em Desarrollo local y planteamiento territorial. Contato: heiroma@ucdb.br
} 
periodo indicado, con el fin de cursar una universidad e tener nuevas experiencias, lejo de sus padres. Fueron también consultados artículo en sites La investigación encuadrase en la tendencia empirio-analitica. Los jóvenes presentaran fuerte dificultades en administrar, principalmente, cuestiones financieras, pues eso no era una práctica común para ellos en los hogares de sus padres. No obstante en otras aéreas ya exista una determinada facilidad - como limpieza de la casa, a inexperiencia en coordinar las actividades de estudio, trabajo, burocracias y vida social aún pesa la vida, la inexperiencia. Aunque en otras áreas ya exista una determinada facilidad - como en la limpieza del hogar, la inexperiencia de la vida de eses jóvenes.

Palabras claves: Dificultades, Académicos, Superación 


\section{Introdução}

O Exame Nacional do Ensino Médio (Enem) como vestibular integrado torna possível o ingresso de alunos em universidade de todo o Brasil e com isso, houve um crescimento no número de jovens que se deslocaram para outras cidades a fim de conseguir o tão sonhado curso de bacharelado, licenciatura ou mesmo tecnológico.

Com o objetivo de averiguar como se organizam os estudantes universitários que não vivem com os pais em Campo Grande no período de 2012 a 2017, como constroem sua autonomia e quais são as dificuldades mais frequentes enfrentadas por eles, foi desenvolvido um questionário qualitativo e quantitativo para apreender como se deu o desenvolvimento de autonomia para obter respostas das experiências deles sobre $\mathbf{o}$ processo de construção da tão sonhada da liberdade.

O questionário desenvolvido foi aplicado em um grupo de 23 jovens na faixa etária de 17 aos 32 anos, permitindo descrever como os jovens adultos em Campo Grande têm se desenvolvido ou não para melhor estarem em sociedade, diante dos inúmeros problemas e do despreparo para o enfrentamento dessa nova fase, na qual podem tomar suas próprias decisões e assumirem seus próprios deveres. Em virtude da impossibilidade de se conhecer previamente o universo dos jovens universitários, sujeitos da pesquisa ora relatada, adotou-se na aplicação do questionário em epígrafe, adotando-se o princípio da saturação, pela qual as respostas tornam-se repetitivas. A pesquisa de campo pode ser caracterizada como sendo de tendência empírico-analítica e de abordagem diagnóstica. A revisão bibliográfica valeu-se de livros e de artigos publicados em revistas online.

O estado da questão foi encontrado em obras de diferentes áreas do conhecimento, como a psicologia e a sociologia, a exemplo de autores como Mattos(2016), García (2016), Ayuso (2007) e Prado (2016).

\section{Universitário}

Em primeiro lugar devemos ressaltar que o presente trabalho faz uma indicação de como tem se desenvolvido (ou não) a autonomia dos jovens, que escolherem morar sozinhos ou longe de seus pais, no período em cursavam a universidade. Para isso tornam-se necessárias algumas elucidações conceituais tidas como relevantes para o melhor entendimento do assunto aqui abordado.

O conceito de liberdade, por exemplo, que muitos dos jovens que fizeram a 
opção de estudarem longe de seus pais, pode aqui ser entendido como: ser livre para tomar suas próprias decisões, agindo conforme seu livre arbítrio desde que outra pessoa não seja prejudicada.

Como afirma Mattos e Castro (2016) para a sociedade o momento da juventude é aquele de se efetivar essa liberdade, pois ainda não se tem tantos compromissos (como trabalho, família) o que permite pensar basicamente em si mesmo e em suas escolhas de vida. Complementa o já mencionado conceito, a ideia de autonomia, que de acordo com Michaelis (2008) pode ser entendido como: livre de poder externo, que se governa por leis próprias, independente. Outro conceito que se deve considerar nesse contexto é o de independência, que segundo Michaelis (2008) significa o que não depende de ninguém ou nada, autônomo, livre. Esses conceitos apesar de muito similares descrevem bem uma das razões que o jovem acaba por decidir sair da casa dos pais, cujo período de universidade torna-se o tempo ideal para isso, pois lhe permite que erre e acerte sozinho, conheça novos caminhos, novas ideias, uma época de desenvolvimento não apenas intelectual, mas também emocional, social e psicológico.

Campo Grande tem sido uma das localidades onde os jovens têm a oportunidade de estudar em universidades públicas como a Universidade Federal de Mato Grosso do Sul (UFMS), Universidade Estadual de Mato Grosso do Sul (UEMS), e universidades particulares que oferecem programas de bolsas em parcerias com o governo em programas como o Fundo de Financiamento Estudantil do Ensino Superior (FIES), Programa Universidade para Todos (PROUNI) entre outros, a exemplo do campi do Centro Universitário da Grande Dourados (UNIGRAN) em Campo Grande, Universidade ANANGUERA-UNIDERP (Grupo Kroton), Universidade Católica Dom Bosco (UCDB) e Faculdade Estácio de Sá. Essas Instituições de Ensino Superior (IES) permitem que pessoas do interior do Estado de Mato Grosso do Sul, assim como de outras Unidades da Federação possam ingressar em cursos universitários. Essas facilidades proporcionam a esses jovens experiências enriquecedoras, cuja escolha implica inúmeras atividades e responsabilidades das quais eles inicialmente não tinham muita clareza.

Esses jovens devem desenvolver maneiras próprias de estudar, trabalhar, fazer novos amigos, organizar tarefas domésticas, pagar as contas e conviver com cobranças, para se tornarem adultos mais rapidamente, já que são responsáveis por si próprios. De toda 
sorte, enfrentam inúmeros desafios ao morar sozinhos em uma fase tão complexa como a da vida acadêmica. Certamente isso compreende um processo de maturação, inerente ao início da vida adulta, e consequente construção da identidade pessoal, ampliação de limites, e sedimentação da autonomia, tomando decisões para sua própria vida e arcando com as consequências dessas mesmas decisões.

Nessa fase de vida os jovens, agora universitários, têm de início um ambiente novo, bem diferente do ambiente escolar do ensino médio, as leituras aumentam, bem como a pressão para obter boas notas, além da necessidade de estágio, horas complementares, novos amigos, que nem sempre são comprometidos com os estudos e que muitas vezes podem influenciar negativamente, para o ingresso em caminhos tortuosos. Outros, todavia, servem como um apoio nas horas mais difíceis, como assevera García (2016), afirmando que os jovens ainda necessitam de um certo suporte para suas reações sociais e esse apoio pode vir da família ou de amizades que podem ser prejudiciais ou não, mas o jovem busca esse apoio ou aceitação de outros.

Por meio dos questionários foram obtidas informações do porquê da escolha dos jovens de virem a Campo Grande fazer a universidade. Seguem as respostas de 3 participantes:

Porque passei no
vestibular em uma
universidade federal.
Fui escolhida pelo
destino
Porque a escola em
que queria fazer
teologia estaria/está
em Campo Grande,
também porque queria
ter a experiência de
morar longe dos meus
pais.
Acesso a um leque
maior de cursos na
UFMS e melhores
oportunidades de
trabalho.

Como se pode depreender das respostas a aprovação no vestibular, no caso em uma a universidade pública, foi o motivo para se mudar para Campo Grande, numa espécie de escolha sem muitas opções, mas que na realidade representou a oportunidade para de início de uma vida adulta.

$$
\text { Pode-se considerar que mesmo que }
$$
uma das características do jovem seja o de ganhar sua independência, ele ainda busca um ponto de referência para iniciar essa nova etapa. O gráfico abaixo evidencia com quem esses estudantes moram. 
Gráfico 1. Com quem os estudantes moram, segundo resultado da pesquisa de campo.

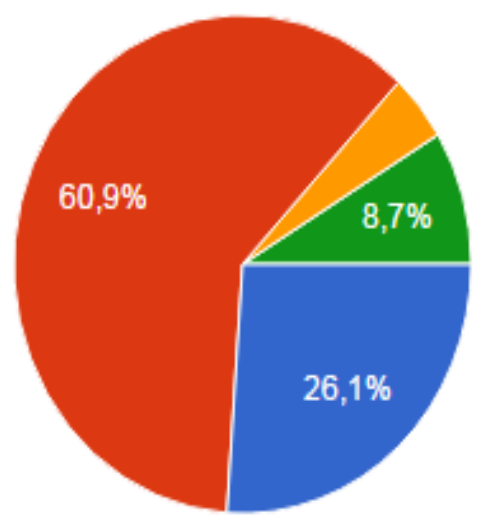

Sozinho(a)

República

Companheiro(a)

Outros

Fonte: elaboração própria.

Como se pode observar, a grande maioria dos jovens opta por morar em repúblicas, muitas vezes pelo fato de não terem que enfrentar completamente sozinhos essa fase. O Guia do Estudante por meio de uma reportagem da escritora Ana Prado (2016) fez o seguinte comentário sobre o tema:

$\begin{array}{lr}\text { Conhecer } & \text { outras } \\ \text { pessoas na } & \text { mesma } \\ \text { situação } & \text { para } \\ \text { compartilhar } & \text { temores } \\ \text { e angústias também } & \text { tamé } \\ \text { ajuda. O importante é } \\ \text { evitar o isolamento - } \\ \text { ele pode atrapalhar o } \\ \text { período de adaptação, } \\ \text { tornando-o muito mais } \\ \text { longo e sofrido do que } \\ \text { o necessário. As } \\ \text { trocas de opiniões, } \\ \text { dicas, com os colegas } \\ \text { e os veteranos, podem }\end{array}$

tornar esse momento de adaptação mais leve, menos estressante.

O ser humano como ser social necessita dessas relações interpessoais por isso busca estar constantemente com outras pessoas, e os jovens universitários ainda mais, pois estão sem os pais para darem o aval em suas ações, sendo assim, procuram alguma afirmação de amigos; parentes; conhecidos pessoas que possam orientar nessa nova fase.

\subsection{Perfil do jovem}

De acordo com o questionário desenvolvido os jovens universitários que foram foco dessa pesquisa são em sua maioria declarados como brancos ou pardos, o que remete à história, pois isso mostra que o 
Brasil ainda tem que melhorar no que muitos jovens socialmente desfavorecidos. concerne à disposição e oportunidades a

Gráfico 2. Raça declarada, segundo dados obtidos na pesquisa de campo.
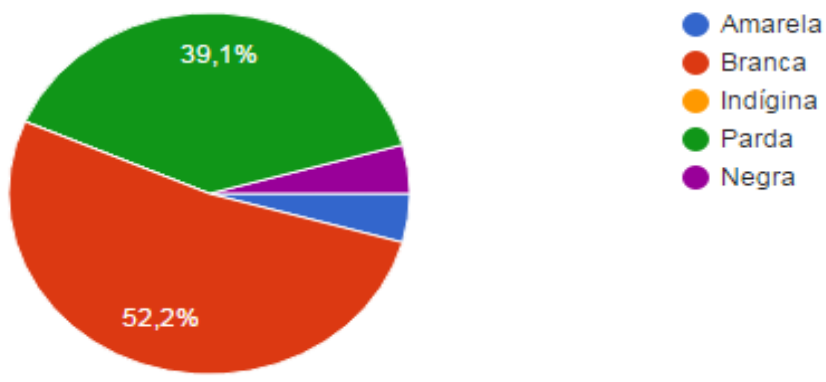

Fonte: elaboração própria.

O perfil engloba a porcentagem de mulheres e homens na situação indicada. Verifica-se em um contexto geral que as mulheres necessitam estudar e se profissionalizar de forma mais especifica para que tenham maiores oportunidades no campo de trabalho, por isso, essas mulheres não podem ter medo de enfrentar novos desafios e conquistar um futuro melhor.

As mulheres são maioria nas escolas, universidades, cursos de qualificação, mas ainda recebem menos do que os homens para desempenhar as mesmas atividades e estão mais sujeitas a trabalhos com menor remuneração e condições mais precárias. Das mulheres ocupadas com 16 anos ou mais de idade, 18,8\% possuíam Ensino Superior completo, enquanto para homens, na mesma categoria, esse percentual é de $11 \%$, apontam dados da Pesquisa Nacional por Amostra de Domicílio (Pnad) de 2014, realizada pela Fundação Instituto Brasileiro de Geografia e Estatística (IBGE). A pesquisa indica ainda que as mulheres são maioria para Ensino Médio completo ou Superior incompleto: $39,1 \%$ das mulheres se enquadram nessa categoria, contra $33,5 \%$ dos homens (PORTAL BRASIL, 2016). 
Gráfico 3. Porcentagem de homens e de mulheres, acordo com os dados da pesquisa de campo.

23 respostas

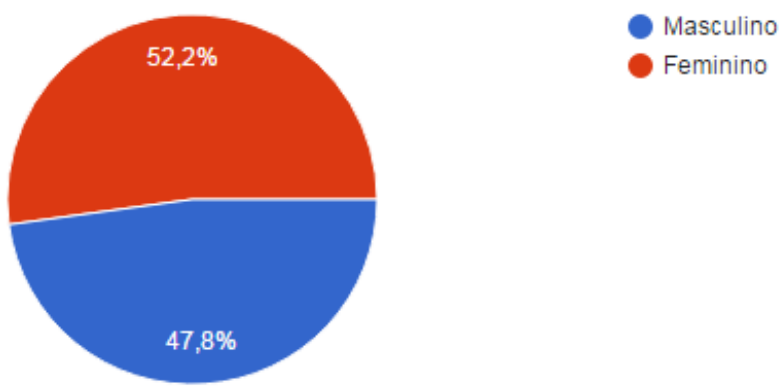

Fonte: elaboração própria.

Por meio do questionário vê-se uma grande concentração na área das ciências exatas e humanas como apresenta no gráfico a seguir.

Gráfico 4. Áreas do conhecimento, segundo as informações obtidas na pesquisa de campo.

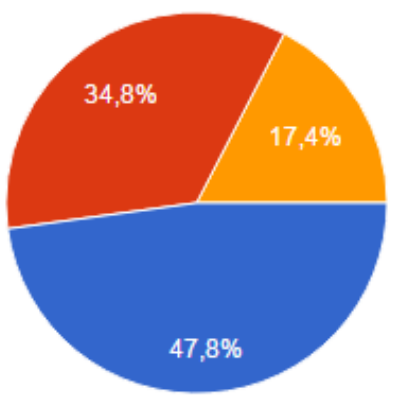

Exatas

Humanas

Biológicas

Fonte: elaboração própria.

Mais alguns dados relevantes para se Estados. Talvez pelas bolsas e projetos em conhecer os jovens pesquisados são os das parceria com o governo, em que esses jovens universidades que podem indicar que a grande maioria está inserida em universidades particulares, mesmo que sejam de outros estudam, permitindo que continuem mesmo que tenham que pagar de algum modo para isso. 
Gráfico 5. Porcentagem das universidades a que pertencem os estudantes segundo a pesquisa de campo

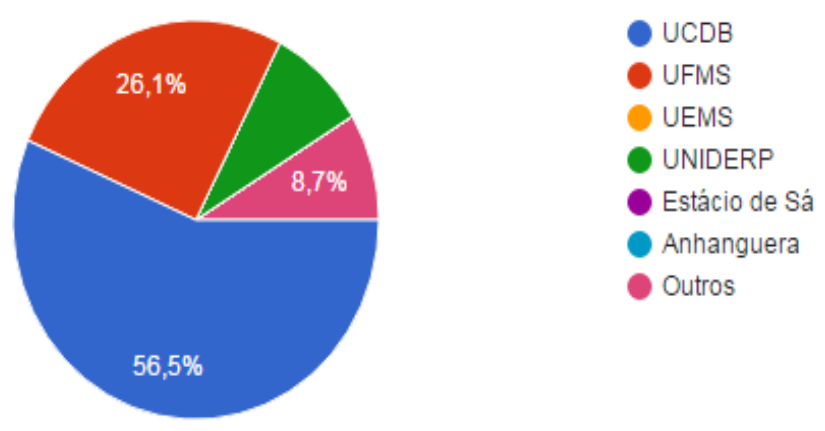

Fonte: elaboração própria.

Os semestres mais frequentes, nos quais esses jovens estão matriculados são o $5^{\circ}$ semestre e o primeiro, como mostra o gráfico seguinte.

Gráfico 6. Semestres de curso, segundo os dados obtidos na pesquisa de campo.

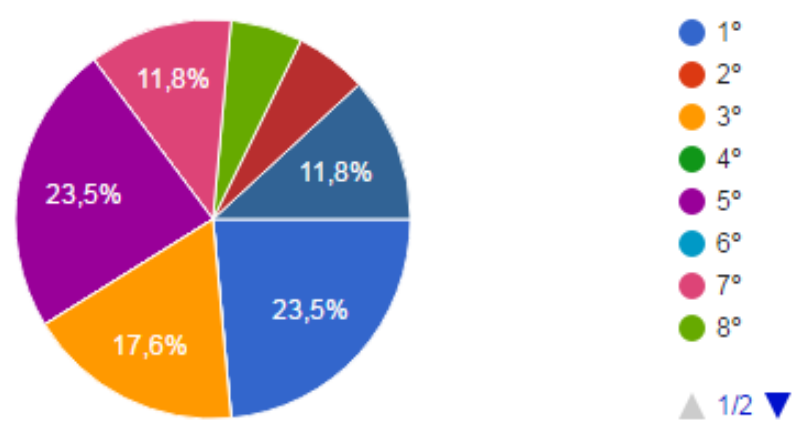

Fonte: elaboração própria.

Foi exposto então o perfil dos jovens entrevistados para uma melhor compreensão sobre a vida deles e quem são e o que buscam no percurso de universidade fora do ceio familiar.

\section{Campo Grande}

Dadas às características locais há que se pensar se Campo Grande tem oferecido oportunidades para esses Jovens se relacionarem de modo salutar. A capital mais 
arborizada do Brasil, segundo o Instituto Brasileiro de Geografia e Estatística (IBGE) Campo Grande tem vários parques e praças que podem propiciar ambiente tranquilo para se passar dias alegres com amigos, além de ruas como a bom pastor que pode proporcionar bons lanches e jantares. Há também outras opções de lazer, como as baladas, ainda muito voltadas para o público sertanejo. Embora Campo Grande não ofereça com frequência outras formas de lazer, voltadas mais para o universo cultural é uma cidade aprazível e boa para se conviver.

Outro aspecto a ser pensado é a questão das universidades públicas com sede no município, como é o caso da a UEMS e da UFMS que a rigor estão despreparadas para receber esses alunos de fora do estado/cidade, pois lhes faltam conjuntos de moradia, espaço de convivência e ausência de bolsa permanência, ainda que exista o Restaurante Universitário (RU) que oferece refeições mais baratas do que os preços convencionais.

Muitos desses jovens vieram de diversos lugares embora pelo questionário a grande maioria tenha vindo do estado de São Paulo, em um olhar superficial e ate pelas respostas dissertativas do questionário podese examinar que esses jovens tem buscado lugares com que melhor lhes oferecem melhores oportunidade profissionais e pessoais, e Campo Grande tem sido esse lugar.

Gráfico 7. Estudantes por estado, segundo as informações obtidas na pesquisa de campo.

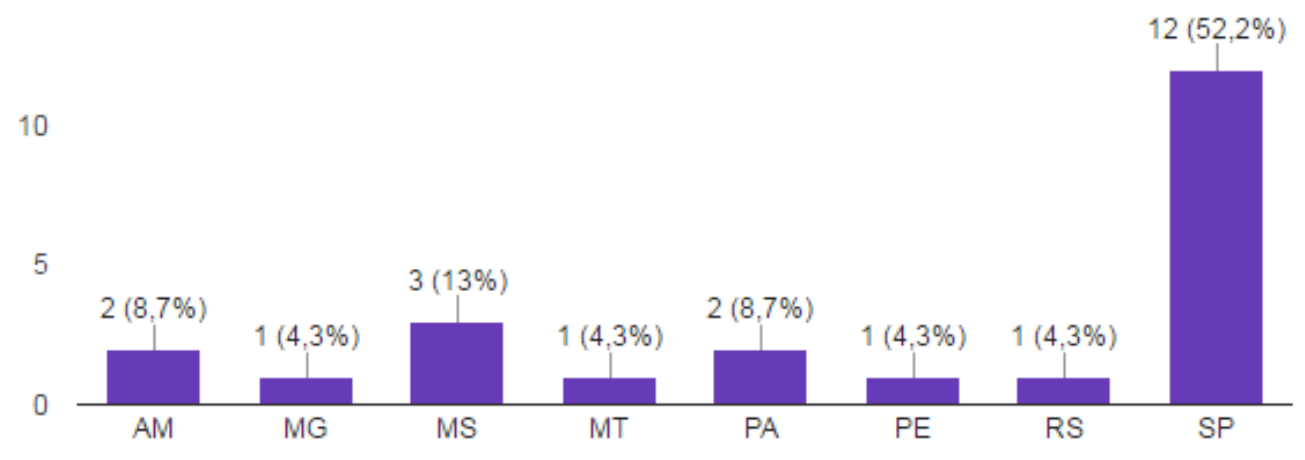

Fonte: elaboração própria.

No questionário fora perguntado onde é o lugar mais frequente onde esses jovens costumam passear. E os resultados foram os seguintes: 
Gráfico 8. Lugar frequente de passeio segundo as informações prestadas durante a pesquisa de campo.

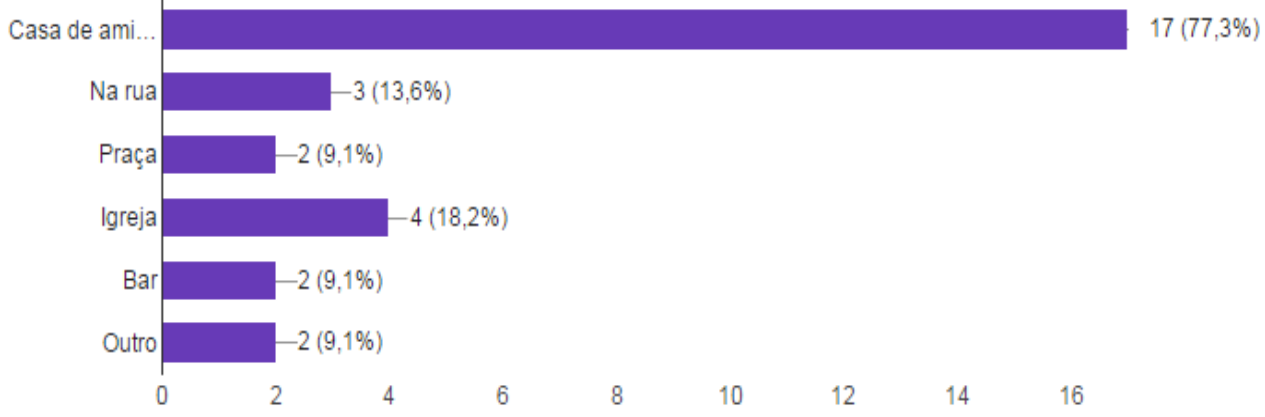

Fonte:

elaboração própria.

Ou ainda as diversões mais frequentes desses jovens, que de acordo com o gráfico é principalmente a casa dos amigos - que podem ser considerados como uma forma de apoio familiar. Como podemos ver no gráfico a seguir e por meio de explicações futuras.

Gráfico 9. Lugar de diversão e Lazer, segundo os dados obtidos na pesquisa de campo.

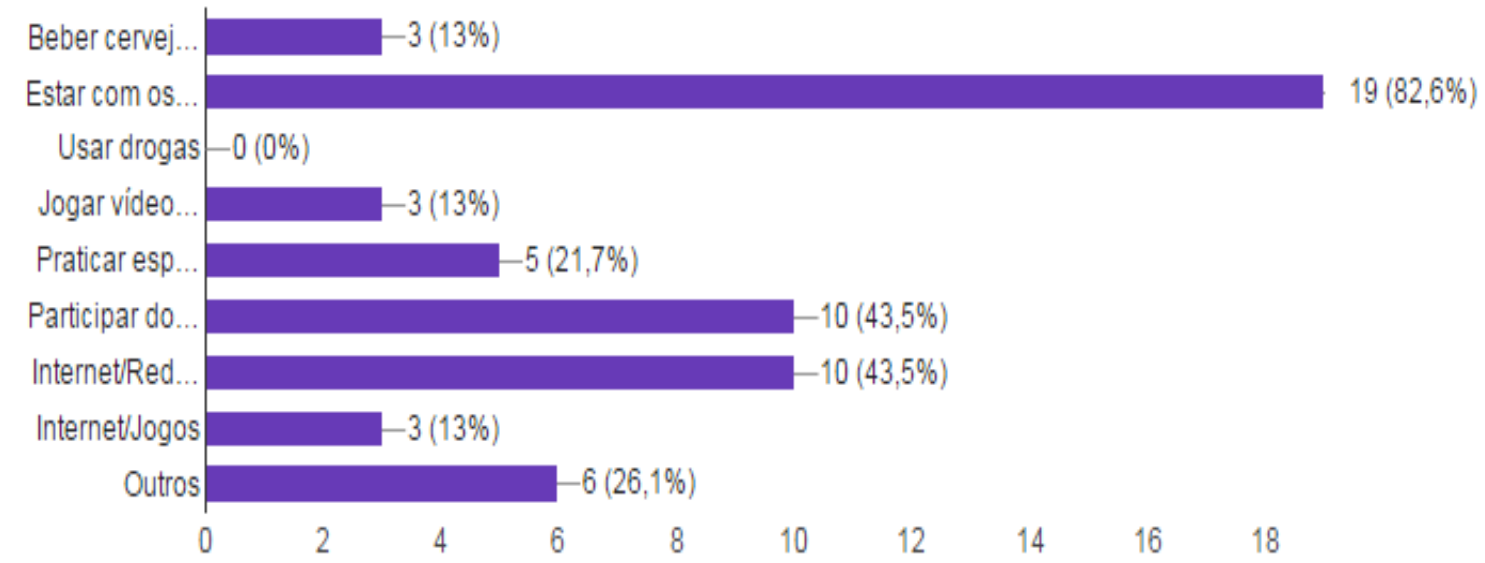

Fonte: elaboração própria.

Todas essas questões deveriam ser

levadas em conta uma vez que as condições e 
qualidade de vida têm reflexo na formação profissional desses jovens, que posteriormente serão os prestadores de serviços à sociedade.

\section{Vantagens e Desafios}

A sociedade em termos tradicionais ensina que o jovem é naturalmente inconsequente, despreocupado e que não têm muitas responsabilidades. E, quando acontece o período de transferência da adolescência para a fase adulta esse jovem quer conquistar a liberdade até então sonhada, o que muitas vezes é barrado pelos pais, pois ao morar com eles subtende-se estar sujeitos às suas regras da familia. Ao surgir a oportunidade de seguir seu próprio caminho, o jovem a agarra com a esperança de auferir a dita liberdade. Mas sair da casa dos pais nem sempre torna as coisas mais fáceis.

Muitos medos podem estar na cabeça do jovem que escolheu ir para outra cidade a fim de estudar, medo de se decepcionar; de errar nas escolhas; não gostar do curso; não se adaptar ao local; sentir saudade da família; a administração da casa entre outras. Esses desafios se apresentam de forma bem rápida, logo ao se iniciar um curso universitário e isso representa uma forte pressão para o jovem estudante, mesmo com as alegrias das futuras experiências.
Quando esses jovens escolhem morar sozinhos ou em república se deparam com a existência de outros conflitos, notadamente com as novas relações interpessoais, se serão amigáveis, se conseguirão pagar as contas, ou seja, se deparam com a realidade que antes estava apenas no pensamento. É comum que muitos de início acreditam que será tudo fácil e acabam gastando mais dinheiro do que têm, acumulando dívidas e preocupações que via regra chegam até seus familiares.

Por meio da aplicação do questionário foi possível perceber que quase todos os jovens ajudam nas tarefas domésticas quando ainda residiam com seus pais, mas não nas questões burocrático-financeiras, fato que os fizeram se sentir despreparados no início da nova fase de vida. No questionário lhes foi perguntado como se mantém em Campo Grande. Muitos responderam que obtém ajuda financeira de mais de um lugar, como dos pais e uma bolsa, ou dos pais e um trabalho/estágio. E, no início quase todos abordaram a respeito da dificuldade em administrar esse dinheiro, visto que querem comprar coisas para si, ou sair com os novos amigos para comer, quase todos tiveram dificuldade em aprender em primeiro lugar a pagar as contas e depois ver o que sobrava para fins de lazer. No gráfico a seguir podem- 
de como se mantém:

Gráfico10. Como o jovem de outro Estado/cidade se mantém em Campo Grande, segundo os relatos na pesquisa de campo

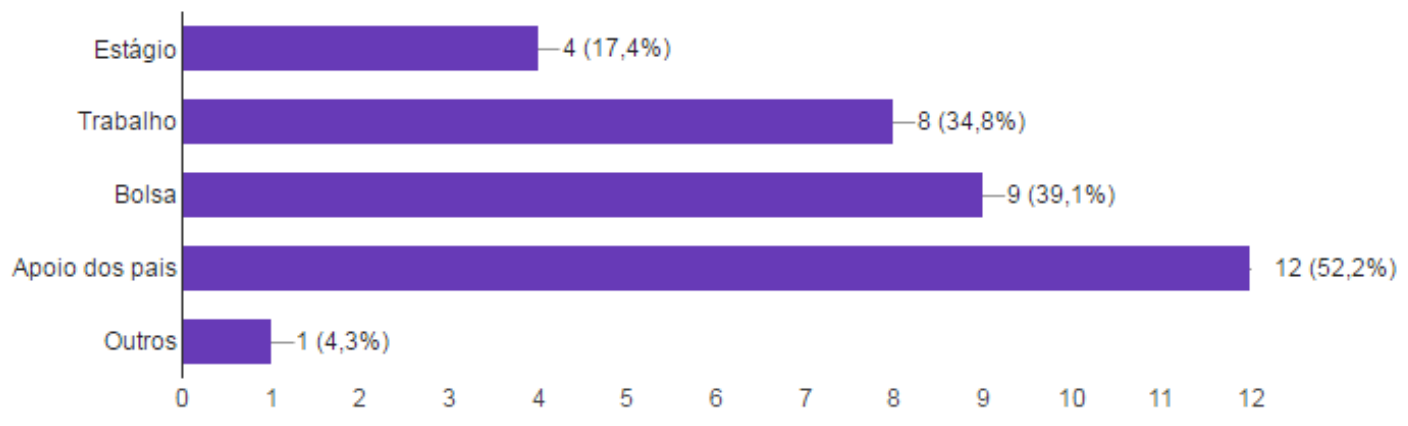

Fonte: Elaboração própria

Como dito anteriormente, o jovem universitário, que estuda em Campo Grande, vindo de outros Estados e cidades do interior de Mato Grosso do Sul enfrenta inúmeras dificuldades em controlar e organizar as prioridades de suas próprias vidas. Via de regra gastam com coisas para si antes de pagar todas as contas ou mesmo comprar alimento, cuja experiência leva ao aprendizado do que é prioridade: vão então pagando primeiro as contas e comprando alimentos e se sobrar dinheiro utilizam para o lazer e coisas pessoais.

Outro problema que se pode verificar em várias reportagens é a má alimentação desses jovens. Algumas IES de Campo
Grande não têm um restaurante universitário a preços que esses jovens possam pagar, por isso muitos deles acabam comendo lanches na rua ou ainda macarrão instantâneo em casa, além dos artigos congelados e pizzas.

Como a renda é baixa e dada a falta tempo aliada à inexperiência para o preparo adequado dos alimentos, o jovem universitário em apreço, termina optando por produtos congelados, macarrão, miojo e pizzas. Anna Simas (2012) por meio do site da gazeta do povo produziu uma matéria sobre a alimentação desses jovens, afirmando que:

A alimentação saudável é algo muito distante da maioria 
dos universitários.

Uma pesquisa feita em setembro pelo

Departamento de Educação Física da UFPR mostrou que a grande maioria não consome frutas $(92,1 \%)$ nem verduras $(80,3 \%)$, mas inclui muito doce na dieta $(69,8 \%)$.

Outra possível desvantagem na vida desse jovem é o acesso ao várias substâncias químicas licitas e ilícitas, que podem prejudicar a si próprio. O gráfico numero 11. mostra as substancias utilizadas por esses jovens e qual delas tem maior frequentes para eles.

Gráfico 11. Substâncias utilizadas pelos acadêmicos segundo os relatos na pesquisa de campo.

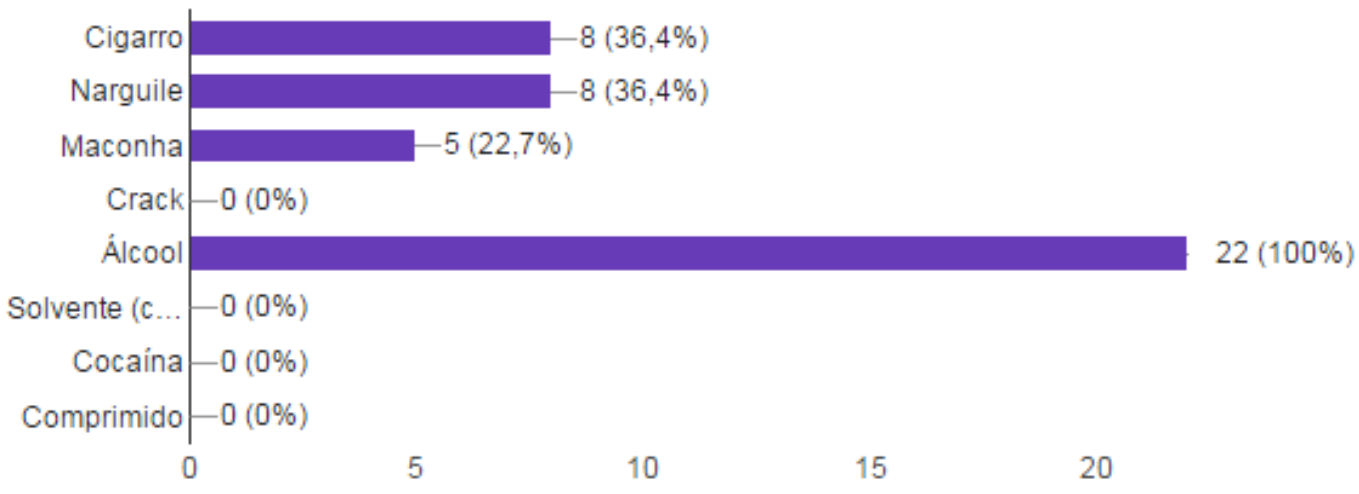

Fonte: elaboração própria.

Pode-se verificar que o álcool tem $100 \%$ de jovens que utilizam que esse componente, embora não seja a o único a ser frequente na vida de muitos desses jovens, ate mesmo pela facilidade de se conseguir diversos componentes dentro e fora $\mathrm{da}$ universidade.

Como se pode inferir, a saúde está relegada a planos secundários, visto que as prioridades são outras. Isso é algo que conta em desfavor do jovem estudante pois pode acumular problemas ao longo de sua jornada universitária.

\section{O Dia a Dia}

Uma das questões do questionário indagava como os jovens têm conciliado a vida profissional, os estudos, o trabalho (aqueles que o tem), as questões burocráticas e a vida pessoal. A grande maioria das respostas enfatiza a dificuldade em conciliar tantas coisas, principalmente no início dessa 
caminhada. Muitos, nas casas de seus pais, apenas estudavam e ajudavam na organização da casa e agora têm que pagar contas, organizar horários, analisar as prioridades sozinhos ou com seus colegas de moradia. O participante $\mathrm{X}$ do questionário afirmou que:

Quando morava com eles, sempre ajudei com afazeres domésticos, porém meu pai nunca expôs as finanças da casa então entendia nada dessa parte antes de morar sozinha. Hoje tento resolver tudo sozinha, imobiliária, contratos, boletos, faço tudo por aqui. Aos meus pais cabem o papel de conselheiros, ligo para eles para tirar dúvidas sobre alguma burocracia.

A autonomia que esses jovens necessitam desenvolver acaba sendo rápida, ainda que possam contar com seus pais como conselheiros, mesmo que não estejam por perto. Então a liberdade vai se tornando mais uma tarefa diária de prioridades, estudo, trabalho, burocracias e vida social por último, quando sobra tempo, como afirma mostra outro respondente da mesma pergunta sobre como conciliar as tarefas:
Estou tentando
descobrir como fazer
isso, tenho uma lista
de prioridades a vida
estudantil no topo, a
doméstica e a social
funcionam quando me
sobra tempo.

Muitos jovens acabam se perdendo no meio das responsabilidades ou até da liberdade de forma inconsequente, por meio de amizades ou com decisões ruins, perdem nas drogas ou no álcool, abandonam a faculdade, decidem fazer outras coisas de suas vidas ou acham que essa liberdade era o mais importante e a seguem. Para isso não acontecer e necessário sempre buscar apoios positivos que os oriente a uma melhor adaptação da nova fase, além da Internet que tem disponível: grupos de pessoas que vivem sozinhas, que fazem universidade dentre outros, que trocam informações, se ajudam, dão dicas; assim como sites e blogs de pessoas que já passaram por essa fase e podem colaborar para um melhor aproveitamento do início da vida adulta.

\section{Conclusão}

O estudo permitiu concluir que o jovem universitário que busca liberdade e que ao optar por estudar em Campo Grande, vindo de outros Estados ou de cidades do interior de Mato Grosso do Sul acaba se deparando com 
diversos desafios em seu dia a dia e que por isso terá que decidir como proceder de modo responsável na construção de sua autonomia.

Verificou-se que as tarefas que eram desenvolvidas na casa dos pais desses universitários serviram de base para que eles pudessem agora agir sozinhos em comparação com aquelas que são consideradas novidade, a exemplo das questões financeiras, nas quais os participantes disseram não ter voz na casa de seus pais. Ainda assim, com a experiência, esses jovens vão aprendendo como construir um plano de independência. Embora muitos jovens ainda estejam buscando construir sua estrutura pessoal de independência, eles têm ferramentas como a Internet que pode auxiliálos no processo.

Mesmo que alguns jovens interrompam seus estudos universitários para seguir outros ideais, descobrem que a liberdade tem seu preço e que ninguém é isento de responsabilidades/deveres e por meio deles é têm a oportunidade de crescer e desenvolver sua autonomia, se formar como um ser adulto inserido responsavelmente na sociedade.

\section{Referências Bibliográficas}

AYUSO, S. Gestión sostenible en la industria turística - retórica y práctica en el sector hotelero español. Tese (Doutorado) Departamento de Geografía. Madrid, Universitat Autónoma de Barcelona, 2003.

MATTOS, A. R; CASTRO, L. R. Jovens e a liberdade: reflexões sobre autonomia, responsabilidade e independência. UFRJ /RJ 2016.

MICHAELIS: dicionário de língua portuguesa. São Paulo: editora melhoramentos,2008.

\section{PLANILHA}

DO

IBGE

Disponível

em:

<www.ibge.gov.br/home/presidencia/noticias/imprensa/ppts/0000000898400512201240102567254

9.xls. em 04/05/2017>. Acesso em: 03/05/2017.

PORTAL BRASIL. Mulheres são maioria em universidades e cursos de qualificação. Disponível em http://www.brasil.gov.br/economia-e-emprego/2016/03/mulheres-sao-maioria-emuniversidades-e-cursos-de-qualificacao Acesso em 09.08.2017

PRADO, A. Como se adaptar à mudança de cidade?. Diponível em: <http://guiadoestudante.abril.com.br/universidades/como-se-adaptar-a-mudanca-de-cidade/>. Acesso em: 21/03/2017.

SIMAS, A. Sozinhos e mal alimentados. Disponível em: <http://www.gazetadopovo.com.br/educacao/sozinhos-e-mal-alimentados1otzao34zemnbzih3iwzue9u6>. Acesso em: 21/03/2017. 
GARCÍA, A. F.. Metateoría sobre la juventude em dificuldade social. Transicion a la vida adulta. Espanã: Posgrado y Sociedad, 2016. 